\title{
The difficulties that people with autism spectrum disorder encounter in different social settings
}

\author{
Khalid Almahrag*
}

*Correspondence: almahrej@yahoo.com

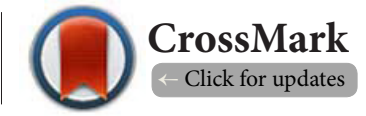

Khalid Mohammed Almahrag, Special Education, King Saud University, Riyadh, Kingdom of Saudi Arabia.

\begin{abstract}
There are people in our society who demand special attention and care like a person with autism. In this paper, we will consider difficulties that a person with autistic spectrum disorders may experience in a societal setting and how the social difficulties affect such a person's life in the family, school, and workplace. First, we will describe social difficulties in a child with autism, then discuss social difficulties in the home, school, and workplace. We will describe the autism factor first then discuss the social difficulties experienced by people with ASD at home, school, and workplace.
\end{abstract}

Keywords: Autism, socially experienced in-home, Social experienced at school, Social experienced in the workplace

\section{Introduction}

In 1908, a psychiatrist coined the term "Dementia Infantilis" to refer to the disorder which causes children to slowly lose the developmental skills they had gained by age two. There has been debate in the autism field about whether Childhood Disintegrative Disorder is a separate diagnostic category. The term autism was coined in 1943 by an Austrian-American psychiatrist. Four altered mental functions have been described earlier by a Swiss psychiatrist, which Bleuler considered fundamental to the diagnosis of schizophrenia. In 1944, Hans Asperger, an Austrian pediatrician, identified a condition called Asperger syndrome, which is also known as Asperger disorder, and was the basis for his theory that Asperger syndrome is a form of autism, which can affect anyone with high non-verbal intelligence quotients and large vocabulary [1]. By the late 1970s, it was clear that language-communication problems were the primary cause of autism and that it had an onset in the first years of life [14]. Andreas Rett first described Rett's syndrome in 1966, and it is a genetic brain disease that typically affects girls between 6 and 18 months of age.

Autism is a neurodevelopmental disorder that affects children and young adults. The current knowledge of what causes autism is still controversial, but discoveries about its pathophysiology may help develop more effective diagnostic criteria [1]. Pensiero, Fabbro, Michieletto, Accardo \& Brambilla
Indicate that autism is a developmental disorder characterized by social communication problems, difficulties with reciprocal social interactions, and unusual repetitive behavior patterns [16]. DSM-IV/ICD-10 was the first definition of autism that was polythetic, had a reasonable balance of sensitivity and specificity, improved reliability for less experienced evaluators, and recognized three disorders added to DSM: childhood disintegrative disorder, Asperger's disorder, and Rett's disorder [14].

Pensiero et al. indicate that Some studies suggest that individuals with autism present abnormal saccadic eye movements due to an altered strategy for exploring the surrounding environment [16]. The results show that autistic individuals show saccadic movement alterations but not classic deficits. A person with autism exhibits abnormal repetitive behavior patterns, including social communication problems and difficulties in reciprocal social interactions. Children's cognitive levels can range from average to above-average intelligence. Children with ASD also may have somatosensory disturbances. That may include hypersensitivity to sounds, smells, touch, textures (oral or tactile), and visual perception distortion. They have difficulties with commotion and crowds.

Some children have hypotonia, fine motor deficits, and difficulties with motor planning. Children with developmental disabilities, including those with ASD, have an increased rate of behavioral or emotional difficulties. Children with ASD may 
Almahrag, Journal of Autism 2021,

http://www.hoajonline.com/journals/pdf/2054-992X-8-2.pdf

have emotional difficulties such as low frustration tolerance, mood swings, over-reactivity, or are easily overstimulated, resulting in agitation and inattention.

\section{Materials and Methods}

Systematic Reviews of Observational Studies have carried out this review. Eligibility criteria for inclusion were original articles based on observational studies regarding genetic causes of dyslexia and early identification. Articles were excluded if they did not meet all the criteria for inclusion.

Three different electronic databases were searched. The initial search was performed on September 26, 2020, and encompassed all original articles published in English. Only "autism" terms were used in the initial search to minimize the risk of missing potentially relevant articles. The screening process was carried out in October 2020. Initially, all articles were screened by heading and abstract, followed by a fulltext screening of the remaining articles. A final hand search through the reference list of the included articles was done on October 28,2020 , to locate additional articles missed by the initial search.

\section{A child with autism experiences social difficulties}

Early deficits in autistic disorder originate in basic behavioral processes such as dyadic interpersonal behaviors rather than the commonly reported joint attention behaviors [4]. Social difficulties are apparent in ASD from an early age. Some children with ASDs do not lift their arms or change posture in anticipation of being held. They often do not make eye contact and ignore others because they lack social interest or an aversion to social interaction [15]. Young children with autism may seem to lack interest in or even be unaware of peers or other children, and they tend to play alone, away from others. Many do not have age-appropriate friends or understand the concepts of reciprocity and sharing of interests and ideas inherent in friendship. Children may gravitate toward adults or older children, or too many younger children. Some may seek out a particular child with a specific solitary interest that dominates the relationship [4].

The communication difficulties experienced by children with ASD often impacts their social development. Autistic children may be completely mute or verbally fluent, although semantic and pragmatic errors often accompany fluency. Even if children are verbal, most have comprehension deficits, particularly in understanding higher-order, complex questions. Some children with autism do not babble or use any other communicative vocalizations. Some children have no spoken language whatsoever and fail to compensate with facial expressions or gestures. Others speak relatively fluently but are unable to sustain a conversation in a give-and-take fashion. Immediate echolalia, a crucial aspect of normal language development in children younger than two years, is pathologic when it is still present as the sole and predominant expressive language after this age. Echolalia is considered a language disorder in children with autism spectrum disorder (ASD) who primarily use verbal communication. Echolalia is defined as the repetition of anotherss speech [15]. Fifty percent of all individuals with autism never speak, making some aspects of social interaction difficult, and those who speak use awkward and often monotone speech. Typically, speech development is delayed in children with autism, with most children having no single words until after age two and no phrase speech until after age 3. Pronoun reversal is common, and speech may be characterized by echolalia or delayed echolalia. In which previously heard words or phrases are repeated later. Many children with autism spectrum disorders (ASD) have difficulty conversing. Autism spectrum disorders do not acquire functional language, and those who do may find it challenging to use it appropriately in social and communicative contexts. With such pragmatic deficits, ASD children cannot contribute original, relevant content and style to discussions [3].

Verbal children with autism may use repetition, concrete, and pedantic phrases and interact with others socially. Sometimes a child's answers to questions seem to "miss the point," especially when such questions do not demand a factual answer but rather require understanding concepts or concept formation. Imaginative play with objects, animals, and dolls can be difficult to come by for some children with autism [11].

Some children with autism are preoccupied with one or more stereotypic and restricted patterns of interest that are abnormal in intensity or focus. Some may ask the same question repeatedly, regardless of the reply. Many become preoccupied with unusual special interests and amass exhaustive information about them. Many children with autism insist on the sameness in their environments or routines and may become very upset if changes occur. For example, a child may insist that all his or her clothing be a specific color or that parents take only specific routes to the store or school. All of that can affect their interaction skills with other children, especially when they play with another child. Some children impose certain behaviors to maintain sameness [1].

Typical motor movements are seen every day in children, such as handclapping, flapping arms, rocking, spinning, and toe walking, and autism is socially unusual and inappropriate. Many children line up toys or other objects or engage in repetitive actions, such as turning light switches on and off or opening and closing doors. Younger children may be fascinated with water and may repetitively transfer water from one container to another.

Children with autism show impairment in social reciprocity. Babies are more interested in objects than in faces, and speech sounds are not particularly salient for them. In contrast, typically developing infants and children find other people very interesting. Children with autism seem uninterested in others, although they will show differential attachment to their parents. 


\section{Social difficulties autism}

In contrast to autism, individuals with autism (ASD) may develop language precociously. As preschoolers, they may speak like "young adults" and use language formalistic in tone. Although children with ASD may use language precociously, their comprehension of complex language is not proportionate with their expressive abilities. Further, their conversational skills are limited by their inability to read nonverbal social cues and restricted interests. The advantage of early language skills in these individuals is superseded by multiple difficulties socializing with other children [3].

Despite interest in relating to others, social reciprocity is notably impaired in autism. It is manifested by a poor understanding of the rules for conversation and social interaction. Taking turns, sharing a focus during the conversation, and listening and responding to what the other person says is skilled a person with AS finds difficult. Eye S or unusual. Contact is insufficient social reciprocity is further compromised by unusual and restricted interests. Individuals with ASD may obsessively on electric fans, air conditioners, maps, weather, historical details, or minute details about political figures. Indepth information about these topics is lacking. For example, a person with AS may know many biographical details about a particular political figure but not describe the political positions of that figure. These peculiarities in conversation and restricted interests impede the ability of a child with AS to relate to peers effectively [3].

Generally, children with A.S.s are socially isolated and demonstrate an abnormal range or type of social interaction. This cannot be explained by other factors such as shyness, short attention span, aggressive behavior, or lack of experience in each area. These impairments can manifest in different ways. For example, the child may not show any interest in other children. Instead, he or she may be a passive participant in other children's play or interact with other children only when play involves his or her obsessive interests. Other children with A.S.s can be socially intrusive or awkward, ask inappropriate questions, come too close to others, or remain aloof. The critical problem is not that they are socially isolated but that they cannot change their behavior to the environmental demands. They always seem out of context. Though willing, individuals with A.S.s do not understand how to go about making friends. They have difficulty understanding the rules about how people relate to each other. Adams, Lockton, Freed, Gaile, Earl, McBean \& Law point that Children with ASD have significant needs in pragmatics and social communication [2]. These children may have emotional and behavioral difficulties and may spend longer time in special provision.

Communication impairments refer to verbal as well as nonverbal communication deficits. Verbal communication includes expressive and receptive language. On the other hand, nonverbal communication includes tone, intensity, the loudness of voice, posture and body gestures, facial expressions, interpersonal distance, and the rhythm and timing of speech. Research has demonstrated that $55 \%$ of the emotional meaning of a message is conveyed through facial, postural, and gesture means, and $38 \%$ of the emotional meaning is carried through tone of voice. Additionally, it was found that only $7 \%$ of the emotional meaning was conveyed through words. Individuals with A.S.s are at a distinct disadvantage in understanding emotional meaning given their deficits in nonverbal and verbal communication [7].

The most apparent impairment in verbal communication is the pragmatic or practical use of language, often resulting in difficulty initiating and sustaining conversations. Individuals with AS use language more for a specific concrete purpose than for social interaction. So, they could talk about the computer in detail and request to use it, but not about how their day is progressing. As a result, conversation lacks cohesion because few links are provided among the thoughts in conversation. Not surprisingly, the term "babyprofessor" is sometimes associated with these children because of their pedantic or scholarly speech. There is often difficulty with the semantics of language or understanding that words may have several meanings. In contrast, the development of grammar and pronunciation typically follows the same pattern as that of normally developing children [7].

Impairments in verbal communication are reflected in nonverbal behavior, including small gestures, clumsy or awkward body language, limited facial expressions, inappropriate facial expressions, or peculiar, stiff gaze. There are several ways children may be detached or have difficulty sensing the feelings of others. They may not look at others, be unable to communicate with their eyes, or come too close to others. A qualitative impairment in social interaction may include a marked impairment in using several nonverbal behaviors such as eye-to-eye gaze, facial expression, body postures, gestures to regulate social interchange, or a lack of interest in showing, bringing, or bringing pointing out objects of interest to others. To summarize, individuals with A.S.s have difficulty interpreting and reading other people's body language and facial expressions, as well as using these forms of communication themselves spontaneously and appropriately [6].

\section{A social problem at home}

Living with autism can be very tough! The demands of raising a child with autism are high, and families frequently experience high-stress levels. Recognizing and preparing oneself for the challenges in store will make a tremendous difference to all involved, including the parents, siblings, grandparents, extended family, and friends [9].

Autistic children do not have any normal relationship with their family and are never aware of the needs and feelings of other people. Moreover, if anyone is hurt or is in distress, they may not respond. In most cases, children run away from or reject their parents when they first see them instead of running toward them when they first see them. Also, they 
Almahrag, Journal of Autism 2021,

are rarely interested in others and do not know what proper social behavior is. For example, they may not react, such as smiling when they hear their mother's voice, nor would they make eye contact with the person taking care of them [12].

Young children with autism may seem to lack interest in, or even be unaware of, peers or other children, and they tend to play alone, away from others. Many do not have ageappropriate friends or understand the concepts of reciprocity and sharing of interests and ideas inherent in friendship. These children may get attached to adults or older children or top much younger children. Some may seek out a particular child with a specific solitary interest that dominates their relationship. Autism spectrum disorder (ASD) is characterized by deficits in social interaction and communication skills. Autistic children, for example, seem to have a difficult time interacting with others, being attentive to others, and sharing their attention with others [14].

Children with developmental disabilities often have an increased rate of behavioral or emotional difficulties, which often frustrate their parents while being at home. Parents may not correctly interpret the child's signals. Children with ASD may have emotional difficulties such as low frustration tolerance, mood swings, over-reactivity, or easily overstimulating. There is convergent evidence that autism suffers from a deficit in multisensory integration. They are less able to discern the presentation motion signals, and atypical responses in autism have been observed [8].

\section{School-related social difficulties}

Although individuals with ASDs usually have average to above-average intelligence, they may demonstrate academic difficulties because they lack higher-level thinking and comprehension skills and tend to be very literal. The ability to reflect on our own and others' thoughts and emotions is a defining characteristic of human cognition. Autistic children show delays in the development of this ability [8]. Furthermore, their problem-solving tends to be poor at school. A significant challenge facing these individuals is their difficulty generalizing knowledge and skills. In other words, they often have difficulty applying information and skills across settings and with different individuals. Moreover, teachers frequently do not recognize the unique academic needs of these students because they often give the impression that they understand more than they do.

Many students with A.S.s learn and process information in a generally incompatible style with the way academic material is presented in many classrooms. Most academic material is presented orally, and these students often have difficulty with auditory input. Although it is speculated that these individuals possess at least average ability to process visual and auditory information, they may have difficulty handling both types of information concurrently. Furthermore, they may require additional processing time to understand words used in the context of sentences and paragraphs [6].
Autistic people with cognitive differences focus on details and cannot see the whole picture or how things fit together. These people have difficulty integrating information, extracting meaning, and distinguishing among relevant details. So, they need structured teaching to highlight relevant details, beginnings, and endings for people like this. It establishes a common way to approach tasks and materials and understand sequences [10].

Indirect and polite forms of speech used in school, such as "Can you take out your textbook?", may be taken as questions by students with ASDs. Thus, their response to this everyday usage may appear inappropriate or rude. Their dilemma is caused by their difficulty interpreting the speaker's intention and motivation [6]. Children are having ASDs experience misunderstanding and mockery when being contacted at school. Children with autism spectrum disorders face additional challenges in conducting themselves at school and in society due to such a situation.

A person with autism often isolates himself in the classroom, seeks secluded areas when in the playground, and shows no interest in team games or activities. The classroom is always a social group and engenders social contact; however, it is a significant source of stress for a child with autism because it needs a group activity.

\section{Social difficulties in the workplace}

People with ASDs cannot find a proper job due to their incapability to organize their behavior, which creates another difficulty in economic society. People with ASDs cannot economically and socially sustain themselves. They need social support and impairment of social interaction and a restricted range of interests; some other characteristics are added: insistence on sameness, poor concentration, poor motor coordination, academic difficulties, and emotional vulnerability. However, some of them can get jobs and live independently or semiindependently. They often succeed in jobs that emphasize specific skills rather than those that require complex interactions with people. Others must depend on outside support. They may live in residential care facilities [12].

Social communication is essential in the workplace. Unfortunately, socially accepted simple communication norms cannot be adopted by people with ASDs. Almost twenty-five percent of such people in any medical practice demonstrate developmental problems at some point caused by interaction in the societal environment. People with ASDs do not have proportionate expressive abilities that are critical for the workplace. Their conversational skills are limited by their inability to read nonverbal social cues and limited, restricted interests. The advantage of early language skills in these individuals is superseded by multiple difficulties socializing with other people [3].

They have difficulties with commotion and crowds. Therefore, people with ASDs do not feel comfortable in the workplace. Noises, usually created by a social setting, annoy people with 
ASDs. Interestingly, autistics have very different perceptions of the world, accompanied by alterations in social cognition. As many as $90 \%$ of autistic individuals have atypical sensory experiences, affecting every sense: taste, touch, audition, smell, and vision [8].

Individuals with ASDs have difficulty interpreting and reading other people's body language and facial expression, as well as using these forms of communication themselves spontaneously and appropriately [6]. All these factors add to the difficulties experienced by people with autistic spectrum disorders at the workplace, giving them almost no ability to have a job where social interaction is essential.

\section{Discussion}

When we address the problems faced by people with autism in the social sphere, we are talking about the extent to which they are socially integrated into their different life situations, including home, school, and work. It may be because of the difficulties they face in managing their interpersonal interactions. For example, it suffers from tuning its visual and auditory responses, which affects its emotions. Our need to create an environment to suit its social needs may make it better to interact with it. That can be provided by giving guidance and instructions to those who will deal with autism either at home or school. It can also be provided by working on the nature of autism and how to interact with it. As such, it is essential that we give as much attention to social awareness programs as we do to autism treatment programs.

\section{Conclusion}

To increase personal autonomy and quality of life, children with ASD must express preferences and make choices. Making choices can decrease avoidance behavior and improve task performance. We think that their educators or caregivers have not offered individuals with severe developmental disabilities many opportunities of choice. Children who have ASD are usually visual learners. When information is presented with visual instead of verbal cues, children with ASD are more successful at accomplishing the presented task.

It is the responsibility of society and individuals to make significant efforts to overcome the social difficulties faced by children with ASDs. Children with ASDs need understanding and patience from the family and the individuals with whom they contact. Reinforcement involves rewarding desired behaviors while ignoring unacceptable ones. It can reinforce any appropriate behavior for longer and longer periods, which could help children with autism to integrate their behavior with society's expectations.

\section{Competing interests}

The author declares that he has no competing interests.

\section{Acknowledgement}

The authors thank the Deanship of Scientific Research at King Saud University for their technical support.

\section{Publication history}

Editor: David Reiss, Imperial College London, UK.

Received: 11-Oct-2021 Final Revised: 20-Nov-2021

Accepted: 14-Dec-2021 Published: 31-Dec-2021

\section{References}

1. Al-Jadiry, Abdil-Monaf and Al-Jadiri, Aseel, "Autism : From Leo Kanner to

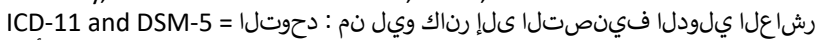
. 100-114, Nov. 2019, doi: 10.12816/0053341.

2. C. Adams et al., "The Social Communication Intervention Project: a randomized controlled trial of the effectiveness of speech and language therapy for school-age children who have pragmatic and social communication problems with or without autism spectrum disorder," International Journal of Language \& Communication Disorders, vol. 47, no. 3, pp. 233-244, Mar. 2012, doi: 10.1111/j.14606984.2011.00146. $\mathrm{x}$.

3. T. Attwood, Asperger's syndrome: a guide for parents and professionals. Philadelphia: Jessica Kingsley Publishers, 2006.

4. S. Clifford, R. Young, and P. Williamson, "Assessing the Early Characteristics of Autistic Disorder using Video Analysis," Journal of Autism and Developmental Disorders, vol. 37, no. 2, pp. 301-313, Sep. 2006, doi: 10.1007/s10803-006-0160-8.

5. Z. HOPKINS, N. YUILL, and B. KELLER, "Children with autism align syntax in natural conversation," Applied Psycholinguistics, vol. 37, no. 2, pp. 347-370, Jan. 2015, doi: 10.1017/s0142716414000599.

6. Glenys Jones, EDUCATIONAL PROVISION FOR CHILDREN WITH AUTISM AND ASPERGER SYNDROME: meeting their needs. S.L.: Crc Press, 2018.

7. R. Jordan, Autistic spectrum disorders in the early years: a guide for practitioners and parents. Lichfield: Qed, 2007.

8. C.Robertson and S. Baron-Cohen, "Sensory perception in autism," Nature Reviews Neuroscience, vol. 18, no. 11, pp. 671-684, Sep. 2017, doi: 10.1038/nrn.2017.112.

9. M. S. Maszak, "The demons of childhood," Washington, D.C, vol. 13, no. 18, pp. 62-70, 2002

10. "Structured Teaching by TEACCH Staff," TEACCH ${ }^{\circledR}$ Autism Program. http:// www.teacch.com/structur.

11. P. J. Wolfberg, Play and imagination in children with autism. New York: Teachers College Press; Overland Park, Kan, 2009.

12. M. Waltz, Autistic spectrum disorders: understanding the diagnosis and getting help. Beijing; Sebastopol, Ca: O'reilly, 2002.

13. F.Volkmar and B. Reichow, "Autism in DSM-5: progress and challenges," Molecular Autism, vol. 4, no. 1, p. 13, 2013, doi: 10.1186/2040-2392-4-13.

14. L. A. J. van der Meer and M. Rispoli, "Communication interventions involving speech-generating devices for children with autism: A review of the literature," Developmental Neurorehabilitation, vol. 13, no. 4, pp. 294-306, Jul. 2010, doi: 10.3109/17518421003671494.

15. P. Pensiero, "Saccadic characteristics in autistic children," PAGE RANGE, vol. 24, no. 3, pp. 153-158, 2009.

16. M. Merg, "ECHOLALIA'S TYPES IN CHILDREN WITH AUTISM SPECTRUM DISORDER," Revista CEFAC, vol. 17, no. 6, pp. 2072-2080, 2015.

\section{Citation:}

Almahrag $\mathrm{K}$. The difficulties that people with autism spectrum disorder encounter in different social settings. J Autism. 2021; 8:2.

http://dx.doi.org/10.7243/2054-992X-8-2 